\title{
On the Study of Chinese Double-false Counterfactual Conditionals
}

\author{
Yujing Yang
}

Wenzhou Business College

Email: joyceyang0901@163.com

\begin{abstract}
The double-false counterfactual conditional is a special category of counterfactual conditionals with particular semantic and pragmatic features which has not been singled out from counterfactual conditionals in Chinese. This paper mainly aims to research the semantics of Chinese double-false counterfactual conditionals whose protasis and apodosis both being false from the perspective from traditional static semantics theory, material implication theory, strict implication theory, coexistence theory and modern dynamic semantics theory. This paper also studies the pragmatic function of Chinese double-false counterfactual conditionals. Both modern and ancient Chinese and English sentences from BCC corpus are compared in this paper in order to testify the particular function of double-false counterfactual conditionals which should be categorized as a type in Chinese. By the analysis from the respective of semantics and pragmatics, the stressed content, emotions and expression characteristics are obtained. The counterfactual conditional sentence is a special form of logical expression and sentiment expression, while the Chinese double-false counterfactual conditionals are not only logically emphasized, but also has the characteristics of exclusive argumentation, which has its unique research value.
\end{abstract}

Keywords: Chinese, double-false counterfactual conditionals, dynamic semantic, pragmatic analysis

\section{INTRODUCTION}

\subsection{Research situation about the counterfactual conditionals at home and abroad}

\subsubsection{Research situation overseas}

The foreign studies on the counterfactual conditionals have gone through a process from the Metalanguage Approaches to the Possible World Semantics. The Metalanguage Approaches refers that consider the "if A then B" as: there are physical laws or a combination of physical laws $\mathrm{C}$, and there is a realistic description of the environment $\mathrm{D}$, so $\mathrm{A} \wedge \mathrm{C} \wedge \mathrm{D}$ contain B. F. P. Ramsey [1] probably was first person that analyzed the truth value of the counterfactual conditionals [2]. As early as 1929, in an article entitled "General Propositions and Causality" he used metalinguistic approaches to give several ways to deal with counterfactual conditionals. Chisholm [3] also expressed such thoughts in one of his article entitled "The Contrary to Fact Conditional" in 1946 [4]. In 1947, Goodman [5] also classified conditionals into counterfactual conditionals (the protasis--the if clause and the apodosis--the then clause of the sentences are both false) and semi-factual conditionals (the protasis is false, the apodosis is true) and the factual conditionals (the protasis and the apodosis of the sentence are both true). In his view, the semi-factual conditionals are the conditionals that the protasis and apodosis do not have any association (logical association or causal association) between each other, and can usually be described as "even if A it still B" (where the protasis A does not tally with the facts). Meanwhile, Goodman also defines the truth condition of the counterfactual conditionals as follows:

The "If A, then B" is true equivalents that, B could be inferred from the $\mathrm{A}$ and some rules and the true sentences that cotenable to A together. Therefore, Goodman believes that the counterfactual conditionals differ from material conditionals and strict conditionals. For case, he demonstrates that the negation rules of counterfactual conditionals are different from that of material conditionals and strict conditionals. He also points out that the converse-negative inference is not applicable to the counterfactual conditionals [6]. 
When Ramsey, Chisholm and Goodman analyzed the counterfactual conditionals, the concept they used are technically the philosophical concepts, such as "rules" or "cotenable". In addition, it is also inevitable that there might be some difficulties when putting it in use. For case, the problems about description of the relevant conditions, the difficulties of the laws and the inference rules those not apply to the counterfactual conditionals (strengthening the protasis inference rules, transitive inference rules and contrapositive inference rules) [7]. After Ramsey, Chisholm and Goodman, although some scholars also analyzed counterfactual conditionals from other perspectives, such as analyzing it by the causal logic of sentences, all of these scholars are still not departed from the metaphorical approach without any breakthrough in the researches of counterfactual conditionals.

Due to these difficulties of metalanguage approach and the lack of formalized models to counterfactual conditionals researches, the Metalanguage approach is inevitably confronted with the bottleneck. Although some scholars have previously mentioned the possible world semantics to research the counterfactual conditionals, the semantics established in the early years can only describe the counterfactual conditionals with a combination of a unary modal operator and truth value mapping [8]. In other words, the metalanguage approach models the counterfactual conditional logic into the modal logic expressed by the unary modal operator and material conditional. None of these practices has provided a properly and widely accepted method of describing counterfactual conditionals [9]. In 1968, R. C. Stalnaker published the essay "A Theory of Conditionals", which has not only provided formal possible world semantics for counterfactual conditionals, but also established axiomatic system $\mathrm{C} 2$ for researches on the counterfactual conditionals [10]. In the $\mathrm{C} 2$ system, he ruled out strengthening protasis inference rules, transitive inference rules and contrapositive inference rules. Therefore, this paper has opened up a new chapter of counterfactual conditions studies. However, there are still some problems in Stalnaker's system, such as Stalnaker-assumption and limit assumption. To avoid such problems, D. Lewis published an article entitled "The Spherical System" in 1973 [11]. This system is an improvement based on the Stalnaker's theoretical foundation and has avoided the disadvantages of Stalnaker's theory. Until now, researches on counterfactual conditionals have come to maturity through the theory of possible world theory. Nevertheless, at the same time when Lewis modified Stalnaker's theory, Lewis' own theory has also been criticized by many scholars and researchers, such as the reasonableness of the similarity concept [12]. Moreover, some scholars have questioned the foundation of both Stalnaker and Lewis' theory, the possible world. Therefore, to research the counterfactual conditionals through possible world theory still has a long way to go [13].

Besides the metalanguage approach and the possible world semantics, the covering law is also strongly correlated with counterfactual conditionals. Over the past half-century, some American and British philosophers in analytical philosophy have shown great interest in the covering law and have conducted in-depth studies on it, including Roderick Chisholm, Nelson Goodman, Michael Slote, Jonathan Bennett and others [3] [5] [14] [15]. The covering law is a kind of theory to explain the counterfactual conditionals, that is, the protasis of a counterfactual conditional combined with the related rules can infer the apodosis of this sentence [16]. This theory plays quite an important role in researching the counterfactual conditionals, which Goodman argues that "the analysis of counterfactual conditionals is by no means a trivial grammar exercise, in fact, it would be very difficult for us to claim that we have a proper philosophy of science if we do not have a way to explain counterfactual conditionals." Overall, there are two directions for the research of counterfactual conditionals. First, as mentioned above, is the possible world theories, which can be utilized to describe the counterfactual conditionals. The other one is the direction of linguistics, and the covering law is of great help to explain the counterfactual conditionals. Although the linguistic approaches occasionally quote the idea of possible world, it merely serves as an adjunct explanation and does not serve as a theoretical nucleus.

\subsubsection{Domestic Research Situation}

However, researches on counterfactual conditionals has a rather relatively late start in China. Unlike English subjunctive conditional sentences could be divided into two major categories: sentence of real condition and sentence of unreal condition according to subjunctive mood remarked by inflection of tense, Chinese was thought to lack the counterfactual thinking because of no change of tense in subjunctive mood. As the result, Chinese counterfactual conditionals received relatively less attention and had not been singled out from hypothetical conditionals. Chao [17] advanced the study of Chinese counterfactual sentences by proposing that many hypothesis conjunctions, such as “如果” “要是” “ 倘若” and so on, could serve as if-clause in Chinese. However, no conjunction was found as an explicit grammatical marker used to deliver counterfactual information.

Since 1980s, Chinese linguists began to systematically study the mechanism of counterfactual information delivery and grammatical markers in Chinese counterfactual conditionals, aiming to identify the distinctive grammatical features of Chinese counterfactual conditionals in comparison with English. Actually, many researchers successively found that 
some typical grammatical markers would indicate counterfactual interpretation. Alfred'F'Bloom [18] conducted an experiment in Hong Kong by asking the Chinese monolinguals to answer a question "If the Hong Kong government were to pass a law requiring that all citizens born outside of Hong Kong made weekly reports of their activities to the police, how would you react?". His finding is that participants in this survey would not answer the question exactly under the reason that event would not happen in reality, and drew a conclusion that Chinese people could hardly do counterfactual thinking since counterfactual sentence does not exist in Chinese. Bloom's conclusion attracted Chinese researchers' wide interest on counterfactual thinking and then counterfactual conditionals were initially studied widespread by Chinese linguists on the mechanism of delivering counterfacutal information in Chinese, and preliminary findings show that although Chinese is an isolating language whose grammar uses word order and function word rather than inflection in Indo-European language, counterfactual conditionals could be judged by the typical grammatical markers of which negative counterfactual connective words including “要不是” “如果不是” and “若非” are used most frequently. The counterfactual information could also be expressed through the truth of protasis and apodosis in counterfacual conditionals without grammatical markers. Xing Fuyi [19] first suggest it as an independent category of conditionals in Chinese until 1985. Chen Guohua [20] identified 5 kinds of grammatical remarks: the aspect and tense of a clause; deixis represented by “早”; modal particle at the end of main clause including “了”"呢”; condition-denoting subordinators including “若不是” “若非” and stressed condition-denoting subordinators. Many other researchers noticed that some particular conjunctions, such as “如果不是” “要不是” “要不” and so on, would indicate counterfactual interpretation. Jiang Yan [21] pointed that if a negation is embedded in the introducer of protasis ofconditionals, the negated condition would lead to unreal result in the apodosis. In this structure, the proposition of protasis expressing a reality is negated, so it derives counter-to-fact result in the apodosis. Therefore, the semantic foundation of Chinese counterfactual conditionals is established on the negator operator represented by “不” [19] [21] [22] [23].

Some other researchers investigated the factors indicating the counterfactual interpretation of the condition and the consequence accordingly. Wang Yuying [24] made an elementary summary of the previous studies and mainly deliberated the elements constructing counterfactual factors. She also constructed a three-layer-context system which included all possible factors for counterfactual meaning, and observed the relation and interaction among all these factors and the effect they generated to counterfactual meaning. Zhang
Min [25] studied the modalization of the counterfactual conditionals with the protasis of "if it were not for". Wang Fang researched the development of semantic theory of counterfactual conditionals. Ni Xiaolan [26] researched the Goodman's theory of counterfactual conditionals. Zhang Wenqin [27] studied the relationship between counterfactual conditionals and David Lewis' philosophy of logic.

Recently, an increasing number of researchers conduct case studies on different sentence structures with different conjunctions, especially the representative Chinese negative counterfactual conditionals marked by “要不是” [25] [28] [29] [30] [31]. Hou Wei [30] classified the Chinese counterfactual conditional into two major groups: with grammatical remarks and without grammatical remarks. He singled out the counterfactual conditionals with a negative grammatical marker embedded in the conditional clause into negative and subjunctive conditional sentence. Based on CCL Corpus developed by Peking University, he discovered that the negative and subjunctive conditional sentence remarked by “要不是”, also called negative counterfactual conditionals, accounts for $83 \%$ of all counterfactual conditionals, so he proposed that “要不是”, model of Chinese counterfactual conditionals as the prototype.

Previous studies have made certain results, and this dissertation will discuss from the perspective of double false counterfactual conditional and wish to draw out of other more valuable opinions upon the theories.

\subsection{The theoretical significance and research questions}

In natural language, the basic form of a conditional sentence is "if A then B", where the conjunctions usually not appear directly. The relationship between protasis and apodosis is a logical relationship, the essence of which is an inference structure that describes the inference relationship between them. The conditional sentence in natural language can be divided into various categories by logic, such as material conditionals, strict conditionals, coherent conditionals, counterfactual conditionals and others [32]. This article mainly discusses the counterfactual conditionals whose protasis and apodosis are both false, which mainly based on the following several reasons:

First of all, As Chinese is a very flexible language, Chinese double false counterfactual conditionals is a valuable research theme. Counterfactual conditionals, also known as subjunctive conditionals, its typical characteristic is the only the protasis or both the protasis and apodosis are subjunctive true but false in reality. In the respect of sentence structure, the subjunctive mood the English counterfactual conditions, no matter in past tense, present tense or future tense, are all introduced by 
“if". Chinese counterfactual conditionals generally need to be combined with context of situation or modal particle to express logical relationship. Some of them are well marked with conjunctions like “如果” or “要是”, while others are not. The research of Chinese double false counterfactual conditionals will contribute to indepth study of the flexibility of Chinese language.

Secondly, in terms of semantics, the subjunctive part and the main clause of both Chinese and English sentences are complementary and can be divided into two types semantically. One is the counterfactual conditionals that the protasis does not follow the objective laws, that is, the hypothesis cannot happen in reality. The other is that the protasis is contrary to the objective facts but it might happen in real life. The latter is diversely shown in Chinese. Among them, as one of the major categories, the counterfactual conditionals that the protasis and apodosis are both false have distinguishing features both logically and semantically. Therefore, analyze the counterfactual conditionals that both the protasis and apodosis are false as a prototype will have great reference signification in both Chinese and English semantics.

The main questions need to be solved in this paper are as follows:

1.What's the principal types of counterfactual conditions?

2.The semantic analysis of Chinese double false counterfactual conditionals.

3.The pragmatic analysis of Chinese double false counterfactual conditional. The Chinese double false counterfactual conditionals have great research values. It will contribute to Chinese native speakers have a deep understanding of Chinese and non-native speakers to learn Chinese well.

\section{THE MAIN CATEGORIES OF COUNTERFACTUAL CONDITIONALS}

\subsection{The double false counterfactual conditionals could be divided into three types based on the purposes}

As the protasis could be false in reality or less likely to be true, counterfactual conditionals can be classified into two categories: the counterfactual conditionals whose protasis is false in reality and the counterfactual conditionals whose protasis is not likely to be true. And the counterfactual conditionals that both the protasis and apodosis are false could be divided into three types based on their different purposes:

(1) The purpose is to emphasize or affirm the protasis;

(2) The purpose is to negate the apodosis;
(3) The purpose is to negate the protasis.

Each of the categories has its own characteristics; the detailed analysis is as follows:

(1) To emphasize or affirm the protasis. Here are some examples:

(1) 如果我起得早一点, 就不会错过那趟火车 了。

'If I get up early, I would not miss that train.'

（2）如要没有伯乐，那么历史上就没有 “高筑 墙, 广积粮, 缓称王” 这句话了。

'If there is no Bole, then there would be no such saying as "Heighten our Fortification, Fatten a Store of Provision, Laten the King's Coronation.",

（3）如果不是在 19 世纪中发现了电磁感应现象, 就不会有电动机、发动机了。

'If the electromagnetic induction phenomenon is not found in 19th century, there would be no electric motor or engine.'

（4）如果我起得早一点, 我也会错过那趟火车。

'If I get up early, I would not get on that train anyway.'

The purpose of the counterfactual conditionals like this is to emphasize or affirm their protasis, which means I get up late. As mentioned in the case (1) and (2), the sentences are respectively emphasized or affirmed "I get up early" and "Bo Le". The case (3) emphasized the application of motors and engines because of the discovery of electromagnetic induction as early as the 19 th century.

It should be noted that in Chinese, according to the law of contradiction of the classical logic theory, it is not allowed to derive two opposite results from the same protasis. However, in the case (4) and (1), their protasises are the same while their apodosises are exact opposite. That is to say, two contradictory conclusions are drawn from the same premise. This is a violation of the law of contradictions in the classical logic theory which is not allowed. However, in expressions for everyday use in Chinese, “如果我起得早一点, 就不会 错过那趟火车了(If I get up early, I will not miss that train.)” and “如果我起得早一点, 我也赶不上那趟火 车 (If I get up early, I will not get on that train anyway.)", these two propositions can be true at the same time in different contexts because the two propositions reflect different things. The former shows that the failure to catch that train is due to his getting up late and the importance of getting up earlier, while the latter emphasizes that the result of missing that train cannot be subjective controlled by the agent but some objective reasons. These cases stress once again that in Chinese, the counterfactual conditionals tend to be more 
a pragmatic concept which emphasizes the specific use of language.

(2)To negate the apodosis.

Besides the purpose of emphasizing or affirming the protasis, there is another type of these counterfactual conditionals, the purpose of which is to negate the apodosis.

\section{（5）如果 $4+4=9$, 那么太阳会围着地球转。}

'If $4+4=9$, then the sun will turn around the earth.'

（6）如果 $4+4 \neq 8$, 那么草就是橙色的。'If $4+4$ $\neq 8$, then the grass is orange.'

It is generally believed that this type of conditionals does not belong to counterfactual conditionals. The counterfactual conditionals require a certain sense of semantic relation between the protasis and apodosis, while there is no such connection between the protasis and apodosis in this type of counterfactual conditional at all. However, although there isn't any connection between protasis and apodosis, the two clauses are still relevant in the case of the absurd degree. The protasis and apodosis are equally absurd and this type of counterfactual conditionals is commonly used in daily life in Chinese, the purpose of which is to negate the protasis of the same degree of absurdity as the apodosis by the absurdity of the apodosis. Therefore, this type of conditionals should be divided into counterfactual conditionals. The apodosis of the case (5) and (6) are “the sun will turn around the earth(太阳会围着地球转 )" and “the grass is orange (草就是橙色的)", both of which are impossible in the real world. Therefore, the 4 $+4=9$ and $4+4 \neq 8$ are negated in this way, that is to affirm $4+4=9$ and $4+4 \neq 8$. Compare with the first purpose, this type of conditionals are normally used to express anger or unconvinced emotion semantically.

(3)To negate the protasis.

Here are some examples.

(7) If the dead people can be revived, I will marry you. (如果人死可以复生, 我就和你结婚。)

(8) If time can go backwards and none of this happens, I will change my mind. (如果时间可以倒流, 这一切都没有发生，我就会改变主意。)

The feature of this kind of counterfactual conditionals is that the protasis is false and contrary to objective facts, which is to say it is a false proposition. As the content of the protasis cannot be realized in the objective world, the apodosis cannot be possible in real life. Logically speaking, for the hypothetical reasoning of adequate conditional, it is an invalid reasoning that to negate the apodosis by negating the protasis However, for the adequate conditional hypothetical reasoning whose protasis is false, it is effective that the negating the protasis is negating the apodosis in Chinese daily expressions. The seemingly paradoxical meaning could also be reasonable in some particular context, because the meaning of Chinese is not entirely based on logic. The Chinese language is like Chinese painting, which pursues the overall effect but the details. As shown in example (7) and example (8),

the protasis of them are "the dead people can be revived (人死可以复生)" and “time can go backwards and none of this happens (时间可以倒流, 这一切都没 有发生)”. Both of these preconditions are impossible in the real world, while in Chinese context, these two sentences are not strange at all. it shows a feeling of regret and helplessness through these impossible preconditions. In classical Chinese literature, this is a typical expression, such as the famous Yuefu ballad in Han Dynasty “Oh Heavens Above! (上邪!)” adopt such kind of technique of expression.

\section{上邪!}

\section{'Oh Heavens Above!'}

汪榕培译

'Translated by WANG Rongpei'

上邪！

'Oh heavens above!'

我欲与君相知,

'I will shower you with my love.'

长命无绝衰。

'It will endure despite the fates above.'

山无棱,

'When mountains don't rise high,'

江水为竭,

'Or rivers have run dry,'

冬雷震震,

'Or winter thunders rumble by,'

夏雨雪,

'Or summer snow flakes fly,'

天地合,

'Or the earth joins with the sky,'

乃敢与君绝。

'Only then shall I give up my love.'

In this poem, the protasis is “山无棱, 江水为竭, 冬雷震震, 夏雨雪, 天地合 (When mountains don't rise high, Or rivers have run dry, Or winter thunders rumble by, Or summer snow flakes fly, Or the earth 
joins with the sky)", and none of these can be true in reality. The purpose is to negate the apodosis, “乃 敢与 君绝 (Only then shall I give up my love)”, which stressed that we will never be apart.

\subsection{The counterfactual conditionals where the protasis is not likely to be true}

Specifically, the protasis is not necessarily false, but it is still unlikely to be true. The differences between such kind of counterfactual conditionals is the protasis is "almost" false, which mean that it still has some possibility to be true but not very high. The common features of these counterfactual conditionals are that the apodosis is false or not likely to be true. By negating the apodosis, such kind of counterfactual conditionals can achieve the effect of negating the protasis. For example:

(1) 如果我能考一百分, 我就可以做最高统帅

'If you can get a hundred on the test, I can be the commander in chief.' (In fact, I cannot be commander in chief.)

（2）要是你能下赢这场棋, 我就倒着走。

'If you can win this chess game, I will walk backwards.' (In fact, I can't walk backwards)

To analyze such counterfactual conditionals, the theory of adequate conditional syllogistic reasoning is necessary. The reasoning process of exmple (7) is: If you can get a hundred on the test, I will be the commander in chief. While in fact, it is impossible that I can be the commander in chief. And the reasoning process of exmple (8) is that if you can win this chess game, I will walk backwards, but I cannot walk backwards in reality, so you cannot will the chess game. What such counterfactual conditionals express is that the negation of the protasis. The protasis is supposed to be not true. Semantically, this type of counterfactual conditionals is similar to the type mentioned in 2.1.3, with the emphasis on negating the apodosis.

\section{THE SEMANTIC ANALYSIS OF DOUBLE-FALSE COUNTERFACTUAL ONDITIONALS}

\subsection{The specific embodiment of double false counterfactual conditionals in traditional static semantics theory}

\subsubsection{The specific embodiment of double false counterfactual conditionals in material implication theory}

The material implication theory origins in Greece and has a long history. The core idea of material implication theory is that the relationship between the protasis and apodosis is absolutely not considered at all and the truth value is determined by its sub-proposition. The logical feature is that if there is $p$, then there must be a q; and if there isn't $p$, it is uncertain whether there is a $\mathrm{q}$ or not [33]. This is quite inconsistent with the usage of natural language. If the protasis is false, the entire conditional sentence is true no matter the apodosis is true or not. The counterfactual conditionals studied in this paper have a false protasis and a false apodosis. Therefore, all the double false counterfactual conditionals are true from the perspective of material implication theory. There are a great many of such examples in Chinese. Among the three kinds of double false counterfactual conditionals, the logical characteristics of material implication theory reflect most obviously in Chinese. Because the material implication theory has breaks down the harsh conditions that to judge the truth value only by logic of the sentence and it pays more attention on the substantive content in terms of semantics.

（1）如果我读了硕士，我就会找到更好的工作。

'If I got the master's degree, I will get a better job.'

(2) 如果我读了硕士, 我也找不到更好的工作。

'If I got the master's degree, I will not get a better job.'

As shown in $(9,10)$, both of them are true according to the logic of the material implication theory.

There are also such examples in classical Chinese literature.

\section{（3）人生若只如初见，何事秋风悲画扇。}

'If lovers keep their first vows and oaths for long, their love would not be thrown as useless winter fans.

The example (11) is a typical Chinese poem that is a counterfactual conditional that emphasizes the protasis. From a logical perspective, according to material implication theory, "f lovers keep their first vows and oaths for long", there must be a "q" as the result; but the apodosis here, "their love would not be thrown as useless winter fans", is not the inevitable result and the truth value of this sentence is true.

\subsubsection{Double false counterfactual conditionals in strict implication theory}

Strict implication theory requires that there must be some necessary connections between the p propositions and the $\mathrm{q}$ propositions, that is, it is impossible for $\mathrm{p}$ to be true and $\mathrm{q}$ to be false. In the double false counterfactual conditionals, since the inherent relationship between its protasis and apodosis is often based on the experience and the order of nature rather than the positive connection on logic, not all double 
false counterfactual conditionals are strictly false. For example:

\section{（4）如果你背叛了你的队伍, 你就是个无耻的} 小人。

'If you betrayed your team, you are a shameless villain.'

In the example (12), the protasis and apodosis are not strictly logically linked, but are built on the basis of factual experience. Therefore, the example (12) is not a strict implication counterfactual conditional. Scholars are also not quite support to consider such counterfactual conditionals as strict implication, because this theory cannot explain the intuitive statement.

\subsubsection{Double false counterfactual conditionals in the coexistence theory}

In the 1960s, N Goodman, N. Rrescher [5, 9] and other scholars have proposed the coexistence theory, which is also called the metalanguage theory of counterfactual conditionals. The theory holds that the counterfactual conditionals cannot directly derive the apodosis from the protasis. The reason why the apodosis cannot be derived from the protasis is that people presuppose certain rules and true propositions in the protasis. The apodosis can only be derived from the protasis together with these rules and true propositions. For example:

\section{（5）如果已经摩擦了火柴，它就会被点燃。}

'If a match has been rubbed, it will be lighted.'

In example (13), the apodosis cannot be inferred by the protasis only, but still necessary to presuppose some propositions such as "the match is in good condition" or "the match is dry enough" etc., so that the match has been lighted can be inferred from striking a match. Therefore, the "striking the match" is coexisting with the conditions that "the match is dry enough" and "the match is in good condition" so that the apodosis can be tenable. Through the theory of coexistence that in the double false counterfactual conditionals, the condition of coexistence enhances the semantics of the original sentence, no matter emphasizing or affirming the protasis, negating the protasis or negating the apodosis.

For example, 糕。

（6）就算用再贵的化妆品, 你的皮肤还是很糟

'If you use expensive cosmetics, your skin is still terrible.'

（7）如果他都能考上北大, 太阳就打西边出来

'If he can be admitted to Peking University, the sun will come out to the west.'
（8）如果他能活过来, 我就跟你去意大利。

'If he can come alive, I will go to Italy with you.'

The example (14) is a counterfactual conditional emphasizing or affirming the protasis and the postulated condition is "if you use expensive cosmetics". Besides the precondition "you will use expensive cosmetics", this precondition also contains some presupposed propositions, such as "you take great care of your skin" or "you want to be pretty". And all these conditions imply a fact that your skin condition is irrelevant with external factors. These presupposed propositions exaggerate the meaning of the sentence in order to emphasize the significance of the protasis. The example (15) is a double false counterfactual

conditional that negates the protasis. "if he can be admitted to the Peking University" contains "he is weak in learning ability" or others. These presuppositions all emphasize the he must not be admitted to the Peking University". The example (16) is a double false counterfactual conditional that negates the apodosis. "If he can come alive" also contains the propositions that "he is dead" or "he is dying" that have greater emphasis on the meaning of "I cannot go to Italy with you". From the perspective of coexistence theory whichever kind of double false counterfactual conditional is, the presupposed propositions they contain enhanced the meaning of emphasis and make it more significant.

\subsection{The specific embodiment of double false counterfactual conditionals in modern dynamic semantics theory}

The traditional static semantics always studies the meaning of a sentence in isolation without considering the changes of context of situation and remote context. Therefore, the traditional static semantics cannot handle a dynamic sentence sequence. These factors have promoted the scholars to research the counterfactual conditionals under dynamic semantics theory. This chapter will explain the double false counterfactual conditionals through dynamic semantic theory and will study their specific embodiment under the dynamic semantic theory.

The Warnbrod theory is one of the representative theories of double false counterfactual conditionals. Warnbrod believes that the counterfactual conditionals should be interpreted in the certain linguistic context and should be the strict conditionals closely related to the context. Warnbrod's main arguments about counterfactual conditionals are that it cannot be determined completely by protasis as in traditional static semantic, but by the protasis of all counterfactual conditionals in its context [34]. Therefore, when studying the counterfactual conditionals, the truth value cannot be judged by the single sentence, but should be studied in its context. If the sentences are studied in 
isolation, the truth value obtained may not be quite accurate, because it might change when put in some certain contexts. Here are some examples.

（9）用再贵的化妆品，也拯救不了你的皮肤。 所以, 用更贵的化妆品且好好护肤, 你的皮肤就会 变好。

'If you use more expensive cosmetics, your skin will still be terrible. Therefore, if you use expensive cosmetics with good skin care, your skin will get better.'

（10）用更贵的化妆品且好好护肤，你的皮肤就 会变好。所以, 用再贵的化妆品, 也拯救不了你的 皮肤。

'If you use expensive cosmetics with good skin care, your skin will get better. Therefore, if you use more expensive cosmetics, your skin will still be terrible.'

As shown in example (17) and (18), "Using more expensive cosmetics" contains the meaning of "take good care of skin". Although the two sentences simply change the order, we will naturally assume that the example (17) is true and (18) is false. However, according to the material implication theory, both of them are true. This phenomenon was first discovered by Heine (1990)[35]. In the example (17), "whether taking good care of skin" is not considered, while in the example (18), since the preceding sentence lists the two concurrent conditions that "using more expensive cosmetics" and "take good care of your skin", people will spontaneously believe the two conditions play the same role. That's why there is a sense of loss of the latter sentence. The reason why material implication theory and possible world theory cannot explain this is because they interpret the sentences in isolation and do not take into account the changes in context.

\section{THE PRAGMATIC ANALYSIS OF DOUBLE-FALSE OUNTERFACTUAL CONDITIONALS}

\subsection{The interaction of emotion and double false counterfactual conditionals}

In addition to the semantic meaning, the counterfactual conditional is also a pragmatic concept itself and it is a concrete application embodied in real life. People use counterfactual conditionals to express their emotions or intentions for the certain events or phenomena, which is a particular effect in the double false

counterfactual conditionals. For example, “就算我 不让他买面包, 他也会出车祸的。(Even if I didn't let him buy bread, he would have a car accident)", expresses the author's strong feelings of unconcern; and “如果没有无产阶级文化大革命, 中国也仍然达不到 中等发达国家的水平。(If there hasn't the Great
Proletarian Cultural Revolution, China still have not reached the level of the moderately developed countries)". This sentence expresses the author's helplessness for the future and regret for the past From a psychological point of view, the formation of a counterfactual conditional sentence is related to the speaker's emotions which could be divided into positive emotions and negative emotions. In general, the negative emotions are more likely to stimulate people to use the counterfactual conditionals, because the negative emotions will lead the speakers' mode of thinking into how to avoid such negative emotions and speakers will imagine a hypothetical situation that is better than reality.

The double false counterfactual conditionals are also closely related to the emotions of the person. The double false counterfactual conditionals often do not reflect strong negative emotions,but express a weak or normal negative emotion instead. For example, “如果我儿子没死 他也上不了大学。 (If my son did not die before, he would not be admitted to university anyway.) " This sentence does not express the extreme pain of the speaker, but expresses a slightly helpless mood. And another example, “如果她瑏得更漂亮些 他也不会娶她。 (If the clothes she wear is more beautiful, he would not marry her.)"Both of these two examples are "memorish" statement, which indicates that the speaker is kind of being slightly jealous or sigh. Therefore, the double false counterfactual conditionals embody the speaker's negative emotions which are not quite strong.

\subsection{The attribution of double false counterfactual conditionals}

One important function of the double false counterfactual conditionals is to remind people learn lessons from the history and prevent the failure recurrence as the two examples mentioned above. Sometimes the double false counterfactual conditionals are also used to explore the reasons of a certain event. For example, when a lighted match goes out, people will analyze the reasons, and the double false counterfactual conditionals always used to infer these reasons, such as: If there is no wind outside the window, the match will not go out; if the match is not wet, it will not go out, etc. These counterfactual conditionals could help to analyze the reasons and research the clues under both of the circumstances. Therefore, when people summarize the reasons, the counterfactual conditionals are often used for analyzing. However, the function of double false counterfactual conditionals is just of opposite. The double false counterfactual conditionals are usually used for exclusion. As the examples mentioned above, “如果有风吹进来, 火柴也不会熄灭。 (If wind blows out of the window, the match will not go out.)" “如果火柴是湿的 它也不会息灰。 (If the match is wet, it 
will not go out.) "It implies that the wind and the wet match is not the reason for match's going out, which is excluded from the real causes. For example, there is director-general is sentenced for 27 years for taking bribe, and first reaction come to people will be “如果他当时拒绝了贿赂, 他就不会落得这个下场了。 (If he refused at that time, he would not result like this)" or “如果没人给他行有, 他就不会落得这个下场了。 (If no one pays that bribe, he will not fall to the point where he is today.) "Both of them, the director-general's refuse and the briber's bribe, are the direct reasons for his being arrested, which has immediately come to people mind. On the contrary, the double false counterfactual conditionals are used for excluding the wrong causes and reasons. For example, “如果他当时拒绝了贿各, 他也不会安然无恙的。 (If he refuses to accept bribes, he will not be safe and sound either)" and “如果没有向他行有, 他也不会安然无恙的。（If no one pays a bribe, he will not be safe and sound)", which imply that the briber and the his rejection are not the reason for his being arrested.

The attribution of double false counterfactual conditionals is not the only feature of double false counterfactual conditionals; the normal Chinese counterfactual conditionals can also show the feature of attribution, while the emotions and the mood expressed by these sentences are different. The former shows the speaker is not care or to comfort someone; the latter tend more to stress on the content. This feature is not the only characteristic in Chinese. It is also reflected in Japanese and English. Nevertheless, considering the specificity of Japanese language construction, most of the Japanese counterfactual conditionals contains obvious marks in sentences, which is not as flexible as Chinese.

\subsection{Influence of background information on double false counterfactual conditionals}

The fact that the apodosis of double false counterfactual conditionals can be inferred from the protasis is often predicated on some background knowledge presupposed by the speaker. In general, the background knowledge is experience of daily life. For example,

“如果王先生早上没有赖床, 他上班就不会迟到了。（If Mr. Wang did not stay in bed this morning, he would not be late for work) ". If you ask Mr. Wang why he wouldn't he not be late for if he did not stay in bed in the morning? He may naturally say that because he has never been late in the past when he did not get up late. Therefore, there is a background message that "anytime, as long as I get up late, I won't be late." This background message is summed up by Mr. Wang from his past experience and it is equivalent to a strict implication proposition: "If I do not get up late I will be certainly not late for work". In addition, the background information of the speaker may come from scientific laws or empirical rules, such as: “就算你把这个石蜡蜡蜘进开水里，它也不会融化的。（If you do not put this paraffin candle into boiling water, it will not melt out anyway)". The background information of these counterfactual conditionals is a scientific law, that is, the paraffin is liquid at temperatures above 60 degrees Celsius. The counterfactual conditional cannot be true without this background knowledge.

\section{CONCLUSION}

This paper mainly studies the Chinese double false counterfactual conditionals from three perspectives. The first part including mainly introduces the research situation home and aboard and the theoretical significance and research content. In the view of the obscurity and flexibility, the Chinese double false counterfactual conditionals is quite a valuable theme to research. Based on the purpose, it is divided into three types, including emphasizing or affirming the protasis, to negate the apodosis and to negate the protasis. By the analysis from the perspective of semantics and pragmatics, this paper detailed analyzes the embodiment of Chinese double false counterfactual conditionals in implication theory, strict implication theory and the coexistence theory. It comes to the conclusion that since traditional static semantics only studies a sentence in isolation without considering contextual changes and contextual relationships, it cannot handle a dynamic sentence sequence, which promotes the study of dynamic semantic theory. The semantics features of Chinese double false counterfactual conditionals are briefly analyzed in Chapter four. It draws a conclusion that the Chinese double false counterfactual conditionals can interact with emotions; and such conditionals have the features of attribution and can be influenced by the background information.

The counterfactual conditional sentence is a special form of logical expression and sentiment expression, while the Chinese double-false counterfactual conditionals are not only logically emphasized, but also has the characteristics of exclusive argumentation, which has its unique research value. Because of the limitations of time and personal capabilities, there are still some deficiencies in this study, and your valuable comments will be appreciated.

\section{REFERENCES}

[1] F.P. Ramsey, D.H. Mellor, Foundations: Essays in philosophy, logic, mathematics and economics Routledge \& Kegan Paul London, 1978.

[2] Q.F. Zeng, Pragmatic Natures of Counterfactual Conditionals, Academic Journal of Zhongzhou, (6) 
(2008) 160-162. https://doi.org/10.3969/j.issn.1003 -0751.2008 .06 .041 .

[3] R.M. Chisholm, The contrary-to-fact conditional, Mind, 55(220) (1946) 289-307.

[4] H.L. Hu, Counterfactual conditionals and the covering law, Journal of Dialectics of Nature, 35(6) (2013)

7-11,

19. https://doi.org/CNKI:SUN:ZRBT.0.2013-06-002.

[5] N. Goodman, Fact, Fiction, and Forecast, 4th edn, Indianapolis \& New York, Bobbs-Merrill Company, 1983.

[6] C. Santamaría, O. Espino, R.M.J. Byrne, Counterfactual and semifactual conditionals prime alternative possibilities, Journal of Experimental Psychology: Learning, Memory, and Cognition, 31(5) (2005) 1149-1154. https://doi.org/10.1037/0278-7393.31.5.1149.

[7] T.K.F. Au, Chinese and English counterfactuals: the Sapir-Whorf hypothesis revisited, Cognition, 15(1-3) 1983, pp. 155-187. https://doi.org/10.1016/0010-0277(83)90038-0.

[8] R.H. Thomason, A model theory for propositional attitudes, Linguistics and Philosophy, 4(1) (1980) 47-70.

[9] N. Rescher, Hypothetical Reasoning, NorthHolland, Amsterdam, 1964.

[10] Y.K. Kuang, Primary Research on the Mechanism of Meaning Construction of Counterfactual Conditionals. Guizhou Normal University, Guizhou 2007.

[11] X.P. Chen, Scientific Laws and Counterfactual Conditionals_ On The New Riddle of Induction, Studies In Dialectics of Nature, 7 (2001) 16-20. https://doi.org/10.19484/j.cnki.10008934.2001.07.004.

[12] F. Jackson, A causal theory of counterfactuals, Australasian Journal of Philosophy, 55(1) (1977) 321. https://doi.org/10.1080/00048407712341001.

[13] N.J. Roese, J.M. Olson, The structure of counterfactual thought, Personality and social psychology bulletin, 19(3) (1993) 312-319. https://doi.org/10.1177/0146167293193008.

[14] J. Bennett, J.F. Bennett, A philosophical guide to conditionals. Oxford University Press on Demand, 2003.

[15] M.A. Slote, Time in counterfactuals, The Philosophical Review, 87(1) (1978) 3-27.

[16] B. Berofsky, The counterfactual analysis of causation, The Journal of Philosophy, 70(17) (1974) 568-569.

[17] Y.R. Chao, How Chinese logic operates, Anthropological Linguistics, 1(1) (1959) 1-8.

[18] B. Alfred, The Linguistic Shaping of Thought: A Study in the Impact of Language on Thinking in China and the West, New Jersey, Lawrence Erlbaum Associates, 1981.

[19] F.Y. Xing, Investigation on the Sentence Pattern "If not p, q" and Its Rhetorical Function, Language Teaching and Linguistic Studies, 1984, pp. 4-12.

[20] G.H. Chen, A Formal Description of Chinese Expressions of Hypothetical Conditions in Comparison with English , Foreign Language Teaching and Research, 1988.

[21] Y. Jiang, On the Counterfactual Reading of Chinese Conditionals.Study and Research on Grammar. Studies and Investigations on Chinese Grammar, Commercial Press, Beijing, 2000.

[22] H. Eifring, The Chinese counterfactual, Journal of Chinese linguistics, 16(2) (1988) 193-218.

[23] W.X. Wang, New Understanding on Modern Chinese Complex Sentence, Shanghai, East China Normal University Press, 1994.

[24] Y.Y. Wang, The ingredients of counterfactuality in Mandarin Chinese, 2013.

[25] M. Zhang, A Modality-oriented Research on Counterfactuals in Mandarin Chinese. Zhejiang University, Hangzhou, 2016.

[26] X.L. Ni, Study on the Theory of Counterfactual Conditionals of Nelson Goodman. Hunan University, Changsha, 2014.

[27] W.Q. Zhang, Counterfactuals and David K.Lewis's Philosophy of Logic. East China Normal University, Shanghai, 2012.

[28] L.M. Cao, Investigation on Syntactic Structure and Semantic Cognition of Chinese Counterfactual Conditionals, Science, Education and Culture, 28 (2009) 79-80.

[29] M.Y. Ma, A three-dimensional Exploration of the "If not" Sentence Pattern, Journal of Ningxia University, 27(6) (2005).

[30] W. Hou, A Study on Chinese Negative and Subjunctive Conditional Sentence. Jilin University, Changchun, 2005.

[31] Y.Q. Xu, Pragmatic Conditions of the Sentence Pattern "If not p, q", Chinese Language Learning, 6 (2012) 21-31. 
[32] V.A. Thompson, R.M.J. Byrne, Reasoning counterfactually: Making inferences about things that didn't happen, Journal of Experimental Psychology: Learning, Memory, and Cognition, 28(6) (2002) 1154-1170. https://doi.org/10.1037/0278-7393.28.6.1154.

[33] M. Xiong, Goodman Paradox and the Inductive Logical System, Journal of South China Normal University (Social Science Edition), (05) (2003), 28-34, https://doi.org/CNKI:SUN:HNSB.0.2003-05-005.

[34] F. Wang, On the Development of Counterfactual Conditional from the Semantic Perspective, Journal of Yichun College, (2015).

[35] B. Heine, U. Claudi, F. Hunnemeyer, Grammaticalization: A Conceptual Framework., University of Chicago Press, Chicago, 1991. 